\title{
Análisis contrastivo (alemán-español) para la traducción del periodismo especializado en ciencia: las noticias de divulgación científica sobre coronavirus
}

\section{Resumen}

El presente trabajo se centra en la traducción (alemán-español) del periodismo científico, más concretamente en las noticias de divulgación científica sobre coronavirus publicadas en periódicos generalistas digitales. Para ello, en primer lugar, compilamos dos corpus textuales, compuesto cada uno de ellos por quince noticias originales en las lenguas española y alemana. En segundo lugar, llevamos a cabo un análisis de los textos, el lenguaje y el discurso de cada corpus. Estas características dan lugar a una relación jerárquica diferente entre escritor-lector o afectan a la ortotipografía. También demostramos cómo, en la traducción de noticias científicas, se trasciende lo lingüístico, al entrar en juego otros aspectos, como la ideología. Posteriormente, comparamos los resultados y determinamos qué características léxico-semánticas y sintácticas comparten y diferencian la noticia de divulgación científica en español y en alemán. Por último, analizamos cómo estas semejanzas y divergencias afectan a su traducción y qué implicaciones tienen.

Palabras clave: coronavirus; covid-19; divulgación científica; noticia científica; periodismo especializado; traducción periodística.

German-Spanish Contrastive Analysis for the Translation of Science Journalism: Science Popularization in News on Coronavirus

\begin{abstract}
The present work focuses on the German-Spanish translation of Science Journalism, more specifically on science news on coronavirus published in online generalist newspapers. To this end, firstly, we compiled two text corpora made up of 15 pieces of news each, originally written in Spanish and German. Secondly, we carry out an analysis of the text, language, and discourse in each corpus. These features give rise to a different hierarchical writer-reader relationship and have an incidence in ortho-typography. Also, we prove how the translation of science news goes beyond the linguistic aspect when other elements, such as ideology, come into play. Later on, we compare the results of such an analysis and determine what lexical-semantic and syntactic characteristics share and differentiate science news in Spanish and in German. Finally, we examine how these similarities and divergences affect the translation process and what implications they involve.
\end{abstract}


Keywords: Specialized journalism; science news; journalistic translation; science popularization; coronavirus; COvID-19.

Analyse comparative (allemand-espagnol) dans le domaine de la traduction du journalisme scientifique spécialisé : le cas des informations de vulgarisation scientifique sur le coronavirus

\section{Résumé}

La présente recherche se concentre sur la traduction (allemand-espagnol) du journalisme scientifique (JC) et, plus particulièrement, sur les informations de vulgarisation scientifique sur le coronavirus publiées dans les journaux numériques de caractère généraliste. À cet effet, en premier lieu, cette étude vise à recueillir deux corpus textuels, chacun d'entre eux étant composé de 15 nouvelles originales en langue espagnole et allemande, respectivement. Ensuite, nous procéderons à réaliser une analyse du texte, de la langue et du discours de chaque corpus, caractéristiques qui donnent lieu à une relation hiérarchique différente entre l'auteur et le destinataire ou qui entraînent des altérations orthotypographiques. D'autre côté, cette étude montre comment la traduction des nouvelles à caractère scientifique dépasse la linguistique, de sorte que d'autres aspects comme l'idéologie entrent en jeu également. Aussi, nous comparerons les résultats et déterminerons les caractéristiques lexicales, sémantiques et syntactiques partagées et différentes entre les informations de vulgarisation scientifique en espagnol et allemand. Finalement, nous analyserons comment ces similitudes et divergences influent sur la traduction et quelles sont les implications qui peuvent conditionner cette tâche.

Mots-clés : journalisme spécialisé; information scientifique; traduction du journalisme; vulgarisation. 


\section{Introducción}

Actualmente, la ciencia y la tecnología son campos con una actividad frenética que están creando a escala global una cantidad de conocimiento sin precedentes. Parte del éxito y la aplicabilidad de sus hallazgos radica en que estos se den a conocer al resto de la sociedad, lo cual entraña una compleja tarea, no solo porque hay que encontrar la forma de difundir a un público general el conocimiento creado, escrito y explicado por expertos, sino también por el interés de este conocimiento, que podríamos atrevernos a decir que, en la mayoría de las ocasiones, es mundial.

El periodismo cientifico (PC), que emana del periodismo especializado $(\mathrm{PE})$, es una de las herramientas que tiene la sociedad para acceder a este conocimiento, pues gracias a su existencia, una persona en España, a golpe de clic, en apenas unos segundos puede conocer uno de los últimos avances científicos logrados en China pocas horas después de hacerse público. Por ello, la labor del PC es evidentemente necesaria, más aún en situaciones como la pandemia mundial de la covid-19, que ha demostrado cómo, en el mundo globalizado en el que vivimos, es necesario e incluso un deber social hacer llegar a toda la población los últimos avances del campo científico y tecnológico.

Huelga decir que la traducción desempeña un papel primordial en el PC, al ser el instrumento para trasladar este conocimiento creado en una lengua a otra diferente. De hecho, tanto es así que Hernández Guerrero (2008b, p. 169) recoge como dato en su trabajo que, según León Gross y su ponencia titulada La ciencia en el escaparate. Análisis de contenido y contenido de análisis, cerca de un $70 \%$ del contenido científico que se publicaba en España era internacional y producido en otra lengua. Nosotros valoramos este porcentaje como desorbitado y entendemos que, en parte, se debe a que, para esa fecha, la producción científica en España era escasa.

Infortunadamente, no podemos afirmar con rotundidad que esta cifra haya disminuido en la actualidad, ya que no existen datos sobre ello; sin embargo, lamentamos que incluso el porcentaje hoy día pueda llegar a ser mayor, al verse la comunidad científica de España en una situación mucho más precaria que la de hace unos años, todo ello provocado por la baja inversión del Gobierno en investigación, desarrollo e innovación, que en el año $2018 \mathrm{ni}$ tan solo alcanzaba la mitad de la media de la Unión Europea, según los datos que nos ofrece eurostat (2019).

Aunque esta reflexión sea tan solo una suposición, la cual necesita recoger más información para ser confirmada o rebatida, no deja lugar a dudas de que el porcentaje de información científica publicada en los periódicos españoles es, en mayor o menor medida, traducido; por ende, nos atreveríamos a considerar la traducción como un agente necesario para las redacciones de los periódicos de España en su labor de divulgación científica.

Si hacemos un repaso por la literatura disponible sobre traducción y periodismo, podemos observar cómo se han abordado ambos elementos desde diferentes puntos de vista, como, por ejemplo, trabajos centrados en las técnicas y las estrategias utilizadas en la traducción periodística (Andújar Moreno, 2009; Hernández Guerrero, 1997, 2004, 2005a, 2005b, 2006a, 2006b, 2008a, 2008b, 2008c, 2009; Reque de Coulon, 2002); estudios que analizan el impacto que tiene la ideología del país, del traductor o de la editorial, en la libertad y la toma de decisiones del traductor periodístico, sobre todo en lo concerniente a asuntos políticos (Carbonell, 2010; Carbonell y Khadija, 2005; Valdeón, 2007a, 2007b) o la relación existente entre gatekeeping (traducido como "selección de noticias" en Hernández Guerrero, 2009, p. 55) y la traducción periodística (Valdeón, 2016; Vuorinen, 1997); obras que hacen un repaso histórico por la traducción periodística (Espejo Cala, 2013; García González, 2004, 2005; Giné y Hibbs-Lissorgues, 2010; Navarro, 2014; Toro Santos y Cancelo López, 2008); trabajos que examinan cómo se desarrolla la labor del traductor en agencias de noticias, a qué desafíos se enfrenta y en qué condiciones 
trabaja (Baya Essayani, 2005; Bielsa, 2007, 2010; Bielsa y Basnett, 2009; García Suárez, 2005); publicaciones dedicadas a analizar la dimensión y el trasvase cultural que implica la traducción periodística (Hernández Guerrero, 2010; Valdeón, 2007c); trabajos que estudian la traducción del PE, más concretamente en el campo de la vitivinicultura (Ramírez Almansa, 2018, 2021).

Si nos centramos en las publicaciones con las que compartimos el mismo objeto de estudio - la traducción del PC-, desafortunadamente no hemos encontrado un amplio número de trabajos (Graiño Knobel, 2015; Hernández Guerrero, 2008b, 2013). Por ello, la relevancia que actualmente tiene el PC no se refleja en el panorama investigador de los estudios de traducción.

De esta manera, con el presente trabajo pretendemos contribuir a dotar de una fundamentación teórica y metodológica la traducción del PC. Más concretamente, en nuestro estudio nos centramos en un análisis contrastivo alemán-español de noticias científicas publicadas en periódicos digitales de carácter generalista, para así conocer las características de este género textual.

En las siguientes páginas, analizamos cuáles son los rasgos más característicos del lenguaje de las noticias científicas sobre la pandemia del coronavirus, tanto en español como en alemán. Este análisis nos ayuda a determinar las semejanzas y divergencias del lenguaje y el discurso de la noticia científica en cada lengua, así como demostramos que la traducción de este tipo de texto va más allá del plano lingüístico, viéndose implicados otros aspectos, como la ideología.

Nuestro estudio se divide en diferentes partes: a continuación aparece una sección donde abordamos el concepto de PE y cómo de este emana el PC. Asimismo, ponemos de relieve las funciones que este tipo de periodismo desempeña. Posteriormente, examinamos el género textual de la noticia científica, así como su traducción.
Luego, llevamos a cabo un doble análisis, a partir de dos corpus textuales: el primero, compuesto por quince noticias científicas sobre coronavirus publicadas en medios generalistas digitales en español, y el segundo, constituido por el mismo número de textos y con las mismas características, pero en este caso en alemán. Dicho análisis contrastivo nos posibilita establecer cuáles son las características del lenguaje y el discurso en la noticia científica sobre coronavirus en cada idioma, las cuales debemos conocer a la hora de enfrentarnos a la traducción alemán-español / español-alemán de este tipo de texto. Por último, tras analizar los resultados de nuestro análisis, ofrecemos una serie de conclusiones.

Con el fin de alcanzar los objetivos enunciados, comenzamos este artículo definiendo qué es el PE, cómo se produjo su génesis y la forma en que, a partir de este, nació el PC. Luego, abarcamos la noticia científica, para centrarnos en las noticias de divulgación científica, más concretamente en aquellas sobre coronavirus publicadas en periódicos digitales generalistas. A continuación, compilamos dos corpus de noticias - uno en alemán y otro en español-, compuesto cada uno de ellos por quince noticias, que reúnen las características anteriormente mencionadas. Entonces, procedemos a llevar a cabo un análisis contrastivo de los rasgos lingüísticos y discursivos de este tipo de texto en cada lengua. Una vez realizado el análisis, examinamos sus resultados y demostramos las implicaciones que para la traducción alemán-español tienen el lenguaje y el discurso que emplea cada idioma en la noticia científica sobre coronavirus publicada en medios generalistas.

\section{Periodismo especializado: periodismo científico}

Actualmente, el mundo del periodismo y el desarrollo que este ha experimentado en los últimos tiempos ha provocado que sus profesionales se enfrenten a la necesidad de especializarse en diversos ámbitos (Salazar Herrera, 2006). De hecho, podríamos comparar esta 
situación con la de la traducción y la interpretación, donde hoy día es evidente la necesidad de ser un profesional especializado, como mínimo, en un campo temático, para poder ser competente.

Al igual que ocurre con los campos de la traducción, en el pasado, el número de especializaciones que englobaba el periodismo era menor, por lo que entendemos que para los periodistas del momento era más fácil conocerlas y abarcarlas. Mercado Sáez (2010) afirmaba que disponemos de mucha más información de la que podemos consumir; por ello, la sociedad exige un PE, con el objetivo de poder seleccionar, según sus intereses, la información y discriminar así aquella que no desea consumir. A esto se suma el esfuerzo de los medios por conseguir una mejor calidad informativa, ahondando más en sus contenidos, a la vez que quiere satisfacer las exigencias de sus consumidores finales, que cada vez están más sectorizados.

Si hacemos un repaso por la historia del PC, no fue a finales de la década de los setenta y comienzos de los ochenta del pasado siglo cuando comenzó a gestarse el PE, como algunos teóricos afirman (Salazar Herrera, 2006, p. 1). Al hablar del PE y su temática, el primer campo de especialización que nació fue el de la economía y las finanzas, de la mano del New York Times, cuya génesis se vio propiciada por la depresión de 1873, que hizo que el PE en este campo actuara como "orientación y previsión de los mercados financieros" (Mercado Sáez, 2010, p. 2). El éxito de esta forma de periodismo llevó al nacimiento del Wall Street Journal en 1889 o del Time en 1923. Con el paso del tiempo, se han ido conformando nuevas áreas, de acuerdo con las exigencias y necesidades de la sociedad.

Sin embargo, el número de ámbitos no ha parado de aumentar. No existe un consenso entre los investigadores sobre qué campos conforman el PE, aunque sí tenemos a nuestra disposición los requisitos que un ámbito del PE debe reunir para ser considerado como tal. Para ello, nos guiamos por diferentes estudios (Enguix Oliver, 2015; Esteve Ramírez, 1999), los cuales Ramírez Almansa (2021) resume en su trabajo, donde afirma que el campo de especialización debe tener coherencia y especificidad semántica, a partir de las cuales se aborda un tema específico y todo ello a diferentes grados de especialización.

Por otro lado, el campo de especialización debe tener un tratamiento específico de la información, alejado de aquel que es propio del periodismo generalista, y en el que se utilicen textos coherentes, fuentes de información específicas y pertinencia con el segmento de audiencia al que se dirige. Además, esta labor debe llevarse a cabo por periodistas especializados en ese campo, en particular que sean capaces, como afirma Esteve Ramírez, de tratar la información "en profundidad" (2010, p. 14).

Asimismo, dentro del PE podemos encontrar diferentes niveles o grados de especialización temática, como ocurre en la traducción. Al respecto, Diezhandino Nieto (1997) considera que "el actual es un periodismo con distintos niveles de especialización, pero casi por definición podría decirse que es especializado. El periodismo no se entiende sin especialización" (p. 86).

Dentro del PE podemos diferenciar varios grados de especificidad, que Esteve Ramírez (2010) divide en tres niveles, ordenados de menor a mayor:

1. Noticias sobre un campo en particular, publicadas en un periódico o revista generalista.

2. Suplementos que acompañan a las publicaciones.

3. Publicaciones especializadas, en las que se trata solo y exclusivamente un ámbito temático.

Cuando se publica una noticia de $\mathrm{PE}$ en un medio generalista de tirada diaria, se tiene poco tiempo para redactarla y, por ende, para 
traducirla, por lo que la información y la terminología empleadas son las que se hallan presentes en las fuentes primarias de las que dispone el periodista. Sin embargo, en el caso de los suplementos, se tiene mucho más tiempo y, pese a estar redactados por periodistas también, la terminología es más especializa$\mathrm{da}$, lo que hace que estos tengan mayor rigor. Lo mismo ocurre de manera gradual con las publicaciones especializadas en la divulgación científica, donde en muchas ocasiones los especialistas, como científicos, economistas o juristas, hacen a su vez de periodistas, y donde el grado de especialización terminológica es el más alto dentro del $\mathrm{PE}$.

Asimismo, la creación de nuevos ámbitos dentro del PE obedece, por lo general, a las demandas y necesidades de la sociedad.

Ante las voces de que se estaba produciendo un superespecialismo, como la denominan Fernández del Moral y Esteve Ramírez (1993) o Hernando Cuadrado (2017), o una superespecialización, como la denominaríamos en los estudios de traducción, en la que los profesionales eran falsos especialistas, es importante tener presente que la razón de ser del PE es "hacer de cada especialidad algo comunicable, objeto de información periodística, susceptible de codificación para mensajes universales" (Fernández del Moral y Esteve, 1993, p. 11).

Al pensar en las áreas temáticas más populares, podemos nombrar el PE en política, deportes o economía. Sin embargo, el área del PE motivo de nuestro estudio es la ciencia, la cual se bautiza como "periodismo científico", también denominado "periodismo de divulgación" o "comunicación científica", según Cervera Rodríguez (2017). Es decir, el PC es un área dentro del PE, la cual se originó una vez acabada la Segunda Guerra Mundial. Fue cuando tuvo lugar tal generación de conocimiento científico y técnico en diversas disciplinas, que una de las formas que tenían los especialistas de ayudar a que la sociedad conociese y pudiese hacer uso de sus investigaciones fue la divulgación científica (Mercado Sáez, 2010). No obstante, aquella época se trata aún de una situación embrionaria del PC.

Hogaño, estamos viviendo una revolución mundial en los campos de la tecnología y la ciencia, donde entran en juego varios países, como China, Corea del Sur, Alemania, Reino Unido o Estados Unidos, en los que el PC es una de las vías más eficaces para la transmisión del conocimiento creado. Prueba de ello es que, durante la pandemia de la covid-19, naciones como la estadounidense, la china, la alemana o la española compiten por encontrar la vacuna contra este virus, y no es infrecuente que, en nuestro día a día, leamos o escuchemos noticias sobre el estado de desarrollo de la vacuna que está siendo investigada por cada uno de los países mencionados. Es aquí donde entra en juego el PC, que ha ido evolucionando y aumentando su valor, a la par que la revolución científica y tecnológica de la que ya hemos hablado.

El PC también ha contribuido a inculcar el deseo de la población a informarse sobre aquello que desconoce o necesita saber, pero que por sus propios medios no puede; por tanto, se trata del instrumento que esta tiene para estar informada en cuestiones del ámbito tecnológico y científico-técnico, para no quedar marginada.

Además, el acceso al conocimiento de los progresos en el ámbito de la ciencia es considerado por muchos, y por nosotros mismos también, como un derecho: "para poder elegir tenemos que estar informados y comprender el razonamiento científico", afirma Cassany (2006, p. 241). Esta reflexión igualmente implica reconocer, como un derecho de toda la sociedad, la oportunidad de tener acceso a la información científica, sea cual sea el estatus socioeconómico. No podríamos imaginar un mundo en situaciones como la pandemia mundial del coronavirus, donde las diferentes sociedades de los países no tengan acceso a un PC que les ayuden a entender qué está pasando y en qué estado se encuentran las investigaciones 
de la comunidad científica de todo el mundo. Podemos relacionar esta idea con el concepto de democracia tecnológica (Fayard, 1988), que defendía que, debido a la revolución científica y tecnológica, los científicos y periodistas deben trabajar por hacer accesible a la mayoría de la población el conocimiento creado por una minoría.

Si entramos a definir el concepto de periodismo científico, podríamos entenderlo, según Avogadro (2005), como aquel periodismo que se encarga de trasladar a la sociedad los descubrimientos y hallazgos de la ciencia y la tecnología, mediante diferentes géneros periodísticos. Los objetivos del PC son, en primer lugar, informar y, en segunda instancia, divulgar. Este último objetivo está íntimamente relacionado con el primero, pero a su vez tiene cierto carácter pedagógico, al tener, de alguna manera, que explicar al lector la información. De modo similar se expresa Cervera Rodríguez (2017), quien afirma que el PC tiene esa "doble función [...]: informar y formar" (p. 136).

\section{La noticia científica y su traducción}

La definición que Avogadro (2005) da del PC manifiesta que este puede materializarse mediante los diferentes géneros que abarca el periodismo tradicional, que se divide en tres grandes bloques: informativos, de opinión e interpretativos o mixtos. Como ya hemos adelantado, en nuestro estudio nos centramos en el análisis del bloque de géneros informativos, más concretamente nos ocupamos de la noticia de divulgación científica. ${ }^{1}$

En la noticia científica como género textual podemos diferenciar tantos campos temáticos como disciplinas (medicina, tecnología, ingeniería, etc.). Para nuestro estudio, hemos elegido noticias científicas que versan sobre

1 Además de la noticia científica, el bloque de textos informativos lo componen otros géneros textuales, como la documentación, el reportaje y la entrevista objetiva (López Sobrino et al., 2009, p. 10). el SARS-CoV2, por lo que el campo temático de las noticias analizadas es la medicina y los subcampos derivados son la epidemiología y la virología.

Centrándonos más en el PC dentro de la prensa generalista, medio del que hemos extraído las noticias base de nuestro análisis, podemos clasificar las noticias científicas en torno a tres bloques, siguiendo la clasificación de Hernando Cuadrado (2017):

\section{Noticias sobre políticas y gestión científica.}

2. Noticias sobre avances y descubrimientos de la ciencia.

3. Noticias sobre temas científicos de situación.

Las noticias del primer bloque son aquellas que guardan un mayor grado de similitud, en cuanto a la estructura y la organización, con las noticias tradicionales. Las del segundo bloque tratan de despertar un mayor interés en la audiencia, al querer dar a conocer los avances científicos, labor que obliga al periodista a "contextualizar la explicación y a destacar la importancia o trascendencia social que pueda tener el acontecimiento científico en cuestión" (Hernando García-Cervigón, 2017, p. 110). Esto convierte este tipo de noticias en vehículo de transmisión entre los científicos y la población general, bloque dentro del cual se categorizarían las noticias de nuestro trabajo. Las noticias del último bloque narran el desarrollo de la ciencia y la contribución de esta a la sociedad, y no transmiten avances de ultimísima actualidad.

Dado el alto nivel de especificidad, valga la redundancia, del campo del PC, debemos categorizar la noticia científica no solo siguiendo criterios determinados por su principal función (informar), sino también por otros parámetros.

Dentro del periodismo, podemos encontrar un amplio abanico de canales, como el radiofónico, el televisivo, el digital o el escrito. Aunque hoy día el periodismo escrito, también denominado "impreso", cuenta con su homólogo 
en formato digital, esto no significa que el periodismo digital esté disponible en el medio escrito y que este último proporcione la misma información y oportunidades que el soporte digital. El periodismo digital, por ejemplo, favorece el debate y se realiza en un texto multimodal que no ofrece el periodismo escrito. La inmediatez que Internet nos brinda, la rápida propagación del conocimiento que permite y su fácil accesibilidad nos ha hecho decantarnos, en esta investigación, por el medio digital frente al físico, sumado también a la multimodalidad, que lo enriquece.

Dentro del periodismo digital existe una clasificación de los textos que lo componen: nos referimos a la propuesta de Cassany (2012). Esta clasificación no se basa en el lenguaje de la noticia en sí, sino que atiende al grado de uso que tiene dentro del texto los elementos que internet nos ofrece. En nuestro estudio, las noticias que hemos seleccionado forman parte del gran bloque de géneros autónomos ${ }^{2}$ (Cassany, 2012, pp. 73-74), ya que están configuradas de acuerdo con las oportunidades que presenta el medio digital. Dentro de este bloque, se definirían como género emergente, ${ }^{3}$ al tener elementos suficientes, fruto del avance del periodismo digital, que las distingue de aquellos géneros del bloque de los géneros transferidos (basados en textos en papel). Nuestras noticias, por ejemplo, tienen un modo de organización propio de una web, con un formato de menú, donde se muestra y se da la opción de acceder a otros contenidos. Esta organización se diferencia considerablemente de la de la noticia en formato en papel, además de hacerlo también por el uso de otros elementos, como el empleo

2 Textos que "dependen de las posibilidades técnicas de la red" (Cassany, 2012, p. 73).

3 Textos concebidos como "Evoluciones sofisticadas de los adaptados, con escaso parecido con los géneros en papel" (Cassany, 2012, p. 74). A su vez, los textos adaptados son aquellos que "Introducen algunas mejoras como trocear el escrito y añadir hipervínculos” (Cassany, 2012, p. 73). de hipervínculos o vídeos, o el hecho de aportar información, como la hora y la fecha en la que se produjo la última actualización de la noticia.

Una vez clasificado y definido el género textual que analiza nuestro trabajo, pasamos a contemplar cómo podemos afrontar su traducción. En el panorama de los estudios de traducción e interpretación, es más que compartida la idea de que a la hora de enfrentarse a la traducción de un texto, no basta con tener un amplio y profundo conocimiento de la lengua origen, el alemán en nuestro caso, sino que también es necesario y de vital importancia conocer a la perfección la lengua meta, enmarcada en el área temática del texto propuesto para traducir —el lenguaje especializado-, así como las principales características del género textual en la lengua meta. De hecho, la fase documental es de gran importancia, ya que ayuda al traductor a encontrar una solución para cualquier tipo de problema emanado del análisis del texto origen (то), así como de la elaboración del texto meta (TM).

Delgado Pugés y Barceló Martínez, con los que compartimos esta concepción, recalcan también la importancia de la documentación en la calidad del TM: "La calidad que presente la traducción dependerá, en gran medida, de la fiabilidad de las fuentes documentales que se hayan consultado" (2011, p. 120).

Sobran motivos para afirmar que el traductor de noticias científicas debe documentarse para su encargo, al mismo nivel o casi que el científico lo hizo para llevar a cabo su trabajo. Es decir, en nuestro caso y con el fin de ofrecer una noticia científica traducida correctamente del alemán al español, no bastaría con conocer las lenguas alemana y española, sino que es igualmente necesario saber cómo es el lenguaje de la noticia científica en español y en alemán, y cuáles son los rasgos de este género textual. Por ello, a continuación, tratamos estos aspectos. 


\section{Resultados del análisis de la noticia científica: lenguaje, lengua y discurso}

$\mathrm{Al}$ abordar el estudio del lenguaje y el discurso presentes en la noticia científica, resultan de gran valor las siguientes palabras de Hernando Cuadrado (2017): "la principal barrera que separa la ciencia de la sociedad es el lenguaje utilizado" (p. 32), dado que la terminología científica no puede sustituirse en su totalidad por otra más cercana a la lengua estándar entendible por cualquier persona de nivel cultural medio. Otros estudios también destacan este aspecto como el de Robles Ávila (2017, pp. 210-211) o González Pérez (2017), "el acceso a esta avalancha de datos, muchos de ellos científicos o tecnológicos, tiene que ir acompañado del acceso a su comprensión" (p. 82).

Si pensamos en la noticia de divulgación científica, concebimos un texto que transmite información originalmente expresada con una alta densidad terminológica y un alto grado de especificidad temática, pensado para la comunicación entre especialistas, y que pasa a dirigirse a una audiencia general, lo que supone que se modifique su lenguaje. Algunos investigadores incluso han definido este proceso - hacer la comunicación entre especialistas entendible al público general - como un proceso de transcodificación (Yriart, 1990), traducción (Puigvert Ocal, 2017) o, según nuestra propuesta, traducción intralingüistica. Por ello, ponemos de relieve las siguientes palabras, ya que el periodista científico, para ejercer su labor, debe tener presente un doble objetivo:

Conocer el tema que va a tratarse y saber contárselo al público de modo sencillo y sugestivo y traduciendo no solo los conceptos, sino todo un lenguaje, y sin dejar un solo término científico (aparte de los que van entrando en la vida cotidiana) sin una explicación (Calvo Hernando, 1997, p. 210).

Es necesario usar un lenguaje comprensible para un público medio, con el fin de comunicar información científica. Para ello, debemos saber cómo se modifica el lenguaje al pasar de un público especialista a uno generalista, por lo que nos son de gran utilidad las siguientes palabras sobre el discurso del PC:

La sustitución del receptor del acto comunicativo científico, que, normalmente, es un especialista, por el público en general en el discurso vulgarizador trae como consecuencia la restricción obligatoria del contenido del mensaje, de su precisión y el cambio en los argumentos de la demostración, no ya por la comprensión o incomprensión lingüística o terminológica sino, fundamentalmente, porque unos y otros - especialistas y no especialistas - no tienen un mismo referente (Gutiérrez Rodilla, 1998, p. 321).

Esto también significa que no podemos pretender, para traducir una noticia científica, que podamos seguir las mismas estrategias de traducción que para traducir un artículo científico de la misma materia. Nuestro análisis de la noticia científica abarca cómo es el lenguaje de la noticia científica y la forma en que este se ordena y se estructura.

Para lograr dicho análisis, nos hemos documentado sobre cómo es el lenguaje de la noticia científica, a la vez que hemos consultado noticias científicas sobre el coronavirus, publicadas entre marzo y junio de 2020 por periódicos generalistas en su versión digital y escritas originalmente en las lenguas española y alemana, extraídas de periódicos españoles, como ABC, El Mundo o El País, y alemanes como ZEIT ONLINE, SPIEGEL o Süddeutsche Zeitung.

El hecho de escoger diferentes periódicos para extraer las noticias de cada lengua no es baladí, sino que con ello perseguimos también dotar al corpus de mayor representatividad y no obtener tan solo los datos lingüísticos y discursivos propios de una sola editorial.

Asimismo, para tener como referencia el mismo número de noticias en cada idioma y asegurarnos de que hemos elegido una cantidad de textos adecuada, hemos compilado un corpus que reúna los requisitos mínimos como para poder estimar sus datos como representativos. 
Para elaborar un corpus ad hoc de temática muy especializada bastaría con quince textos, según el trabajo de Ramírez Almansa (2021), el cual establece esta cifra tras haber analizado los estudios más importantes sobre lingüística de corpus y hacer un cálculo medio de las recomendaciones de los expertos.

El análisis se ha dividido en diferentes secciones que, en algunos casos, cuentan con subsecciones. En todo momento, cada parte del análisis queda apoyada con ejemplos reales procedentes del corpus. El objetivo del análisis es abarcar todos los rasgos del lenguaje y el discurso de la noticia científica especializada en la COVID-19, cuyo conocimiento debe tenerse en cuenta ante una posible traducción del texto. El registro de los textos que conforman el corpus se ofrece en el Anexo.

\subsection{Características léxico-semánticas}

\subsubsection{Uso de terminología especializada}

Al pensar en la noticia científica, podemos imaginar a priori que el uso de los tecnicismos es erróneo y que deben buscarse equivalentes más comprensibles; por este motivo, es común que los términos se sustituyan por palabras de la lengua estándar, para facilitar su comprensión. Por ello, debemos tener cierta cautela al emplear los términos, los cuales con bastante frecuencia han sido creados a través de formantes grecolatinos.

Asimismo, existen numerosos ejemplos de términos, sobre todo del ámbito médico, como nombre de enfermedades, conocidos por el público general (términos banalizados).

En ocasiones, la presencia de los términos especializados es inevitable y estos pueden no ser conocidos por el lector, pero en ese caso y para hacer la tarea de comprensión más fácil, se suelen acompañar de una aposición que los defina o de un aporte de ejemplos, de incluso una explicación a través de metáforas o comparaciones. Aunque esta práctica pueda resultar engorrosa y en cierto modo dificulta la capacidad comunicativa del texto, es preferible a emplear una equivalencia al término errónea, que no funciona. Estas técnicas servirían en cierta medida para desterminologizar los términos (Campos, 2013), es decir, para hacerlos accesibles de cara a su lectura por un público que no es especialista.

Un caso de una palabra de la lengua general que actúa sustituyendo a un término común entre especialistas en los textos que hemos leído es "gotícula", que en español se ha intercambiado por "gota" o "gotitas" y en alemán por Tröpfchen ("gotitas"); de hecho, esta forma aparece en noticias de Uhlmann (2020a) o Kupferschmidt (2020). Las gotículas tienen un tamaño microscópico imperceptible al ojo humano, pero para poder hacer entendible al lector de qué se trata, se sustituye por "gota" o "gotita".

Como traductores, también debemos estar siempre actualizados al continuo cambio que caracteriza a la terminología científica, dada la rapidez de los avances, que hacen que un término adquiera nuevas acepciones dentro de una misma temática, o incluso que tenga significados diferentes, según el campo temático en el que se utilice.

Con la llegada de la pandemia del coronavirus a nuestras vidas, como podemos ver en los ejemplos, términos antes nada usuales en el ámbito del PE han irrumpido con fuerza, como "seroprevalencia" (en alemán, Seroprävalenz) (véase Ejemplo 1) o Hydroxychloroquin (hidroxicloroquina) (véase Ejemplo 2). Estos ejemplos son tan solo dos casos de los numerosos términos que suelen aparecer en cualquier texto del PE en el que se hable sobre la COVID-19.

Ejemplo 1:

Uno de los objetivos es conocer la seroprevalencia en la ciudad, es decir, el porcentaje de habitantes que han pasado la enfermedad (Sevillano, 2020). ${ }^{4}$

4 En los ejemplos, los resaltados en cursiva son nuestros. 
Ejemplo 2:

Die Uniklinik Tübingen hat eine klinische Studie mit dem Wirkstoff Hydroxychloroquin vorerst ausgesetzt, wie der SPIEGEL aus dem beteiligten Forscherteam erfuhr. Das eigentlich für die Behandlung von Malaria und Autoimmunerkrankungen zugelassene Mittel wird auch als mögliche Behandlung von Covid-19 gehandelt (Köppe, 2020b).

Otros ejemplos de uso de términos son "zoonosis" (Galocha y Domínguez, 2020), en alemán Zoonose; "loratadina" (Lucio, 2020), en alemán Loratadin; "senescencia" (López Sánchez, 2020a), en alemán Seneszenz; Reproduktionszahl $R$ (Kupferschmidt, 2020), en español "número reproductivo básico" (RO), o Sauerstofftherapie (Le Ker, 2020), en español "oxigenoterapia".

\subsubsection{Uso de neologismos}

Dado que el objetivo de la noticia científica es dar a conocer los últimos hallazgos de la ciencia, con frecuencia nos vamos a encontrar palabras de nueva creación, formadas ad hoc para designar una nueva realidad hasta el momento desconocida. Su presencia es frecuente, al avanzar mucho más rápido la ciencia que la labor de codificación de lingüistas, lexicógrafos y terminógrafos.

Como se observa en los ejemplos, en el caso del alemán podemos destacar el neologismo Superspreader del Ejemplo 3, en español "supercontagiador", creado ex profeso con motivo de la pandemia mundial del coronavirus, según recoge la Real Academia Nacional de Medicina de España (2020).

Ejemplo 3:

Gehen sie während dieser Zeit zu einer Großveranstaltung, können sie leicht zum Superspreader werden: falsche Zeit, falscher Ort. "Zwei Tage später könnte derselbe Mensch sich genauso verhalten und man würde nicht das gleiche Resultat sehen", sagt Kucharski (Kupferschmidt, 2020).
También hemos advertido el caso en español de "Covid-19" del Ejemplo 4, igual en alemán, que, al no estar aún codificado por expertos de la lengua, existen varias formas de ortografía diferentes, escribiendo solo la inicial en mayúscula - la más usada en alemán-, todo en minúscula o escribiendo toda la palabra en mayúscula. Nosotros optamos por la última opción que es la que recoge Fundéu (2020): COVID-19.

\section{Ejemplo 4:}

La localidad quedó señalada como la zona cero de la región donde la pandemia del $\mathrm{Co}$ vid-19 ha golpeado con más fuerza: la Comunidad Autónoma de Madrid (CAM) supera los 68.000 positivos y las víctimas mortales confirmadas se acercan ya a las 8.700 (Ley, 2020).

Ni siquiera existe un consenso en cuanto al género; nosotros nos decidimos por el femenino frente al masculino, ya que la sigla está formada a partir de la enfermedad y no del virus, pese a que esta forma sea menos usada. Es decir, seguimos la recomendación de la Fundéu (2020), que también reconoce el uso del masculino, aunque no lo aconseja; otras instituciones, como la Real Academia Española (2020), reconocen y admiten ambos usos.

Otros ejemplos de neologismos hallados en el corpus son es el nombre del virus que provoca el coronavirus tipo 2 del síndrome respiratorio agudo grave o sARs-CoV-2 en su forma abreviada, procedente del inglés severe acute respiratory syndrome coronavirus y Superspreading Events (Kupferschmidt, 2020), en español "eventos de supercontagio", el cual, en lengua alemana, se utiliza tal cual es extraído del inglés.

\subsubsection{Uso de abreviaciones en forma de siglas y acrónimos}

El uso de estos elementos en la noticia viene motivado por la influencia del lenguaje científico-técnico, donde son comunes, pero también se debe a motivos de economía lingüística. 
Al hablar de siglas, también podemos hablar de "siglas préstamos", como, por ejemplo, la Agencia Europea del Medicamento, cuya sigla en español es EMA por influencia del inglés (European Medicines Agency). Asimismo, ocurre que siglas procedentes del inglés forman ya parte del discurso científico español, como ADN, claro ejemplo de desterminologización. Dicho término desterminologizado ha aparecido en nuestro corpus alemán: DNA (Le Ker, 2020).

$\mathrm{Al}$ emplear las siglas, puede primero ofrecerse la expresión y a continuación, entre paréntesis, indicarse la sigla o, al contrario, se ofrece la sigla y se proporciona entre paréntesis su forma desarrollada. Como podemos ver en el Ejemplo 5, se hace uso del término, acompañado de la sigla PCR (en alemán también PCR), lo cual no significa que aparezca igualmente en los textos tan solo en su forma abreviada, formándose tanto en español como en alemán a partir de la expresión en inglés: polymerase chain reaction (en español, "reacción en cadena de la polimerasa"). En este caso, la sigla en español puede aparecer tanto la forma abreviada (Ley, 2020; López Sánchez, 2020b; Sevillano, 2020) como combinada con la expresión (Cortés, 2020a). En alemán, solo aparece la forma abreviada (Uhlmann, 2020b; Zinkant, 2020).

Ejemplo 5:

La reacción en cadena de la polimerasa (PCR) de las muestras obtenidas de la garganta se completa en un laboratorio de microbiología (del centro sanitario si dispone del equipo o en el Centro Nacional de Microbiología) y consiste en un método que permite amplificar la secuencia del genoma viral (Cortés, 2020a).

En el Ejemplo 6 advertimos el uso de Weltgesundheitsorganisation (WHO), en español Organización Mundial de la Salud (OMS), donde podemos ver cómo, en alemán, la expresión se ha adaptado, pero la sigla no, al formarse del inglés World Health Organization, al contrario que ocurre con el español, donde, en ambas formas, sea sigla o forma desarrollada, se han creado adaptándose al español. También, como ocurre con PCR, OMS puede aparecer en alemán combinándose la forma abreviada con la expresión (Köppe, 2020b; Kupferschmidt, 2020; Le Ker, 2020; Stukenberg, 2020; Uhlmann, 2020a, Süddeutsche Zeitung; Weber, 2020) o solo la expresión. En español, hemos hallado el uso de la combinación de expresión y abreviatura (Ansede y Galocha, 2020), solo la expresión (Cortés, 2020b; Galocha y Domínguez, 2020) o solo la forma abreviada (Sevillano, 2020).

\section{Ejemplo 6:}

Die Weltgesundheitsorganisation (WHO) und Frankreich haben Studien deshalb vorerst abgebrochen. Nun zieht auch Deutschland nach. [...] Danach wird entschieden, ob die Studien fortgesetzt werden. An der Entscheidung sind auch die zuständige Ethikkommission sowie das Bundesinstitut für Arzneimittel und Medizinprodukte (BfArM) beteiligt (Köppe, 2020b).

En el Ejemplo 6 también advertimos un caso de sigla para referirse a una institución alemana, más concretamente al Bundesinstitut für Arzneimittel und Medizinprodukte (BfArM), traducido al español como Instituto Federal de Medicamentos y Productos Sanitarios, homólogo alemán de la Agencia Española de Medicamentos y Productos Sanitarios (AEMPS). Entendemos que esta tendencia está en parte influenciada por el lenguaje científico, así como por razones de mera economía lingüística a la hora de hacer referencia a institutos o centros de investigación y demás instituciones. En el español, también hemos encontrado otros casos de abreviaturas que hacen referencia a instituciones como $\mathrm{CNB}$, que se refiere al Centro Nacional de Biotecnología, o cSIc, cuya expresión desarrollada es Consejo Superior de Investigaciones Científicas (Galocha y Domínguez, 2020). Este tipo de siglas - las que se refieren a instituciones propias de cada país - podríamos considerarlas un culturema.

También podemos encontrar otros casos de siglas que, en su forma abreviada, tanto en 
español como en alemán, se han construido a partir del inglés, como, por ejemplo, Single Nucleotide Polymorphism, que da como resultado SNP (Le Ker, 2020) y que, en el caso del alemán, su forma desarrollada se sigue usando en inglés, pero en español sí se ha adaptado: "polimorfismos de nucleótido simple o único". Lo mismo ocurre con "síndrome de disfunción orgánica múltiple" (Nieves, 2020b), en su forma desarrollada, o en su sigla, MODs —igual en español y alemán-, procedente del inglés Multiple organ dysfunction syndrome, en alemán Multiorganversagen.

\subsubsection{Uso de diferentes figuras lingüisticas}

La noticia científica, en su objetivo de hacer inteligible el contenido científico que transmite y, a su vez, para la audiencia media, se vale del uso de figuras como las metáforas, el símil o la analogía, o de recursos como la cita o la definición. El uso de estos elementos, dentro de la traducción del PC en forma de reportajes científicos, ya fue mencionado por Hernández Guerrero (2013).

Pese a que, al ver el nombre de algunas de estas figuras, como la metáfora o la analogía, nos venga a la cabeza el texto literario, no es que el PC lo sea, pues la metáfora y la metonimia son más que frecuentes en el lenguaje científico-técnico. Al fin y al cabo, el objetivo de estas figuras es establecer una relación entre un término o idea científica, y el discurso general manejado por la audiencia receptora.

Un claro ejemplo de este uso es la metáfora del Ejemplo 7, donde, para reproducir la idea del tamaño del coronavirus, se dice que 320000 virus colocados verticalmente en fila india tendrían el tamaño de una pieza Lego ${ }^{\circledR}$. Las figuras mencionadas servirían como las "conexiones entre nudos" o "vínculos entre nudos científicos y nudos no especializados" (Cassany et al., 2000, p. 79).

\section{Ejemplo 7:}

Rund ist das neue Coronavirus, stachelig und winzig. Reihte man 80.000 davon aneinander, würde diese Kette nur einen Zentimeter messen. Könnte man 320.000 Viren hintereinanderlegen, hätten sie die Länge einer Legofigur (Simmank, 2020, ZEIT ONLINE).

Como podemos ver en el Ejemplo 8, se hace uso de la metáfora "im Kampf gegen Corona" (en la lucha contra el coronavirus) para representar al lector la idea de que los políticos y la sociedad civil en general han concebido la pandemia como una guerra o una batalla, donde la buena gestión y control de esta se traduce en una victoria o, por el contrario, en una derrota.

\section{Ejemplo 8:}

Besonders Us-Präsident Donald Trump
hatte für das Malaria-Medikament ge-
worben und es unter anderem als "Ge-
schenk Gottes" im Kampf gegen Co-
rona bezeichnet (Köppe, 2020b).

En el Ejemplo 9 vemos cómo el periodista describe la aparición del coronavirus y su rapidísima transmisión con la metáfora "la tormenta epidemiológica perfecta".

Ejemplo 9:

La pandemia de la Covid-19 ha superado al argumento de cualquier película de catástrofes. Es, según los científicos Yong-Zhen Zhang y Edward C. Holmes, "la tormenta epidemiológica perfecta” (López Sánchez, 2020b).

A estos ejemplos podemos también sumar la analogía que se hace en $A B C$ al comparar la mutación del virus con "Los superhéroes de Marvel" (López Sánchez, 2020b), dada la rapidez y facilidad con la que se contagia y trasmite, o la metáfora "como cócteles de terapias" (Nieves, 2020d), que se hace para referirse a la aplicación de diversas terapias aún no ensayadas en pacientes con coronavirus para comprobar si son o no efectivas.

Otra metáfora que se ha utilizado en alemán para representar la alta tasa de contagio y dispersión del coronavirus y lo fácilmente que este se transmite respecto a otros virus es " $\mathrm{Co}$ - 
ronaviren sind Cluster-Champions" (Kupferschmidt, 2020), en español "los coronavirus son los campeones del grupo".

Por otro lado, es importante también destacar que estas técnicas permiten reformular el significado de un término, aportando una especie de sinónimo que nos facilita evitar el uso de la denominación empleada entre especialistas.

\subsection{Características sintácticas}

En la sintaxis de la noticia de divulgación científica se funden rasgos propios del lenguaje científico y rasgos propios del lenguaje periodístico de la noticia. Los rasgos hallados son la mezcla de estilo personal e impersonal, el uso de los tiempos verbales, las aposiciones explicativas, el uso del estilo indirecto, la apelación al lector, los mecanismos de cohesión y otras características sintácticas.

\subsubsection{Mezcla de estilo personal e impersonal}

En el discurso científico se opta por el empleo de la voz pasiva refleja o pasiva con ser y el verbo en tercera persona, para que así dé la sensación de objetividad (Gutiérrez Rodilla, 1998, p. 326).

Varios trabajos (Hernando Cuadrado y Hernando García-Cervigón, 2006; Hernando García-Cervigón, 2017; Myers, 1990) defienden que la sintaxis en la noticia de divulgación científica se caracteriza por poner en marcha mecanismos que aporten precisión y objetividad, entre los que podemos destacar la impersonalidad y la ausencia de cualquier marca personal, así como sintagmas nominales abstractos en la función del sujeto, formas de cortesía y el uso de la voz pasiva.

Aunque, en el periodismo generalista, el uso de la voz activa es común, sobre todo en aquellos casos en los que se desea hacer hincapié en el agente que ejecuta la acción, en cambio, en el caso de la noticia divulgativa es frecuente emplear la voz pasiva, por influencia del lenguaje científico, donde predomina la voz pasiva, ya que, por lo general, lo que importa es centrarse en el hecho en sí y no en quien lo lleva a cabo.

Igualmente es de vital importancia destacar que al emplear la pasiva refleja se suele anteponer el sujeto a la construcción del verbo, invirtiendo el orden (Hernando García-Cervigón, 2017, p. 113) como ocurre en el Ejemplo 10 "a medida que el coronavirus se extiende". También puede aparecer la pasiva refleja sin marca de sujeto.

\section{Ejemplo 10:}

El protagonista de esta historia es un virus minúsculo e insignificante, de nombre sARsCoV-2, que parece proceder de murciélagos y al que la evolución le ha permitido ser muy contagioso entre personas y causarles neumonía. [...] Dejando al margen la letalidad, a medida que el coronavirus se extiende, sigue evolucionando en cada célula, en cada persona y en cada país y va acumulando nuevas mutaciones. [...] Para nuestra tranquilidad, difícilmente estos cambios harán a los virus más letales, puesto que «La alta virulencia puede reducir la transmisibilidad del virus si el hospedador está demasiado enfermo», según este investigador (López Sánchez, 2020b).

El uso del plural de modestia incluye, en lo escrito por el autor del texto, a la audiencia que lo lee, lo que sirve para disminuir la fuerza de lo que se escribe, como podemos ver en el Ejemplo 10 "Para nuestra tranquilidad...". Esta técnica puede utilizarse en construcciones imperativas, con verbos modales o aunando ambas. Sin embargo, en el PC, el periodista también personaliza los hechos, proporcionando siempre su fuente e incluso puede dar su opinión en calidad de experto en primera persona del singular.

Como podemos ver en el caso del español con el Ejemplo 10, en un mismo párrafo es posible observar cómo se entremezcla un estilo personal con uno impersonal, llegando a usar varios tipos de voz pasiva o haciendo uso de la tercera persona. En alemán, la balanza se equilibra más hacia un estilo impersonal, mediante 
el uso de varias formas de la voz pasiva o la tercera persona, como vemos en los Ejemplos 11 y 12 .

\section{Ejemplo 11:}

In den ersten Studien wurde berichtet, dass diese beiden Kernsymptome bei mehr als drei Viertel der Patienten auftreten. Kürzlich vermeldete das Robert-Koch-Institut, dass Fieber und Husten jedoch nur bei etwa 40 bis 50 Prozent der Infizierten in Deutschland vorkommen würden (Bartens, 2020).

Ejemplo 12:

Das Robert-Koch-Institut (RKI) geht davon aus, dass die Erreger hauptsächlich über den direkten Weg übertragen werden. [...] Man weiß, dass bis zu zehn Prozent der Erkrankten an Durchfällen leiden. (Uhlmann, 2020a).

\subsubsection{Tiempos verbales}

Es importante destacar que, en las definiciones científicas difundidas como verdades universales, se utiliza el presente atemporal, el cual les aporta validez en todo momento en el que se lean. Ambos idiomas coinciden, además, en el uso del presente para describir datos científicos al ser universales o emplean el presente histórico cuando hacen referencia a hallazgos del pasado.

Asimismo, los verbos dicendi, que son aquel tipo de verbos declarativos denominados "verbos de habla", empleados con el fin de expresar una reflexión, una emoción, una creencia o una acción comunicativa, enmarcados en la noticia científica, también suelen utilizarse en presente, ya que acompañan a construcciones que apoyan las verdades universales. El tiempo verbal predominante en los verbos dicendi del corpus en español es el presente, optando por este tiempo en doce casos, frente a los tres casos en los que se combina con el pasado. Por otro lado, el alemán no sigue esta tendencia, advirtiendo que el uso de los verbos dicendi en presente tan solo se observa en diez textos, con convivencia de este tiempo con el pasado en tres de ellos y utilizándose tan solo la forma de pasado en dos casos.

\subsubsection{Aposiciones explicativas}

Las aposiciones contribuyen a aclarar el contenido y pueden unirse a la información que complementan mediante un segmento de carácter sustantivo, o bien por medio de construcciones que también cumplen la función de aposición, al ir formadas por una proposición subordinada de participio o de relativo adjetiva explicativa. Igualmente, pueden hacerse aposiciones mediante el uso de las rayas (véase Ejemplo 13), los paréntesis (véase Ejemplo 14) y las comas. Asimismo, es común el uso de los dos puntos para expresar enumeraciones explicativas. El uso de la raya es una práctica más frecuente en el corpus alemán que en el español, al utilizarse este modo para construir una aposición en cuatro textos alemanes, frente tan solo a uno en español.

\section{Ejemplo 13:}

Deshalb hinken die offiziellen Angaben zur Zahl der Infizierten ungefähr zehn Tage - womöglich sogar länger - hinterher (Simmank et al., 2020).

\section{Ejemplo 14:}

Todo esto ocurre porque "emplean una polimerasa de ARN (una enzima que actúa como copiadora de material genético) intrínsecamente dada a cometer errores, con lo que sus genomas acumularán mutaciones en cada ciclo de copia", explica Grubaugh. [...] Todo este trabajo permite estudiar, a nivel molecular, toda la historia del sARs-CoV-2: qué virus es, si es nuevo, cómo se transmite, cuál es su reservorio, qué factores provocaron su aparición, cómo evoluciona y cómo se adapta (López Sánchez, 2020b).

Es más usual en alemán que en español la convivencia de construcciones de aposición mediante raya y paréntesis en un mismo texto, estando presente esta tendencia en siete textos en lengua alemana, frente a tres casos en len- 
gua española. El uso del paréntesis con el fin de expresar este tipo de construcción es más reiterado en español que en alemán, utilizando este elemento diez noticias españolas y tan solo tres noticias alemanas.

Es también digno de mención que todas las noticias, tanto españolas como alemanas, incluyen aposiciones mediante comas; incluso, un texto en español y otro en alemán solo hacen uso de este mecanismo para expresar este tipo de construcción.

Por lo general, las aposiciones pueden también materializarse en forma de las figuras señaladas en la sección "4.1.4. Uso de diferentes figuras lingüísticas", como podemos ver en el Ejemplo 7.

\subsubsection{Uso de estilo directo}

En el PC, al igual que ocurre en un artículo científico, se hace uso de citas textuales de expertos, con la salvedad de que en la noticia científica no se ofrece una referencia bibliográfica, sino que las palabras textuales reproducidas siempre aparecen entrecomilladas, indicando su autor (véase Ejemplo 15). Al igual que ya ocurre en el periodismo generalista, la primera vez que se hace referencia a una persona se indican su nombre y apellidos, y para volver a referirse a la persona suele hacerse solo con el apellido o con un rasgo que lo identifique, como su profesión, cargo, etc. (véase Ejemplo 16).

\section{Ejemplo 15:}

\begin{abstract}
"Wir brauchen neue Ideen", sagt Schulleiter Henry Tesch. "Intensives Testen könnte uns ermöglichen, den Schulalltag etwas zu normalisieren." (Hecking, 2020).
\end{abstract}

Ejemplo 16:

Ahora, un nuevo estudio recién publicado en Current Biology y dirigido por Weifeng Shi, del Instituto de Biología de Patógenos en la Primera Universidad Médica de Shandong en China, acaba de dar un nuevo respaldo a la teoría del origen natural. [...] Desde que se descubrió en 2005 que los murciélagos fueron el reservorio del coronavirus del SARS - dice Shi-, ha habido un gran interés en ellos como "especies reservorio" para enfermedades infecciosas, especialmente porque tienen una gran diversidad de virus de ARN, incluidos los coronavirus (Nieves, 2020a).

Como podemos ver en el Ejemplo 15, en alemán existe la peculiaridad de que en el empleo del estilo directo es común, para representar una declaración hecha por la misma persona, fraccionar la cita en dos partes, separadas por sus correspondientes comillas, y en la división de la cita introducir el verbo dicendi y el nombre de su autor.

\subsubsection{Apelación al lector}

En la noticia de divulgación científica y como estrategia para captar la atención del lector es común la formulación de preguntas interrogativas directas parciales, que no esperan ser respondidas, sino que se aporta a continuación su respuesta.

Las apelaciones al lector se pueden hacer efectivas mediante distintos mecanismos, como podemos ver en el Ejemplo 17, a través de una pregunta en la que se incluye al lector, o dirigiéndose directamente a la persona que lee el texto, como ocurre en el Ejemplo 18: "Liebe Leserin, lieber Leser" (Estimada lectora, estimado lector). Tan solo hemos hallado un ejemplo de apelación al lector en el caso de las noticias en alemán -Ejemplo 18-, frente a las seis noticias en español que sí las incluyen, siendo, en el caso del español, todas las apelaciones mediante preguntas, como se muestra en el Ejemplo 17.

\section{Ejemplo 17:}

Los pacientes asintomáticos son, a la vez, alivio y preocupación en las estrategias contra la pandemia global del coronavirus. Pero, ¿qué significan a nivel microscópico? ¿Puede ser el propio plan evolutivo del 
Covid-19 para expandirse más y mejor entre la población humana? (Biosca, 2020).

Ejemplo 18:

Liebe Leserin, lieber Leser, mit Geld kann man nicht alles lösen, heißt es - vieles aber eben doch. Auf die segensreiche Wirkung gut gefü1lter Krisenkassen setzt jetzt auch die EU-Kommission. Am Mittwoch kündigte deren Chefin Ursula von der Leyen an, 750 Milliarden Euro für den wirtschaftlichen Wiederaufbau mobilisieren zu wollen (Stukenberg, 2020).

\subsubsection{Mecanismos de cohesión}

Estos sirven para relacionar los diferentes párrafos (Hernando García-Cervigón, 2007, pp. 160-164, 2017, p. 121; Portolés Lázaro, 2001), como, por ejemplo, a través de la reiteración léxica (Casado Velarde, 2006, p. 19), en la que cada párrafo puede comenzar por la misma palabra o por sinónimos, o también mediante el uso de marcadores discursivos (Hernando García-Cervigón, 2017, p. 122), como a continuación o de este modo.

En el caso del alemán, hemos encontrado conectores ordenadores de transición, como andererseits, opositivos de concesión, como trotz, o el consecutivo damals.

\subsubsection{Otras características sintácticas}

También puede omitirse el determinante que acompaña al sujeto plural que sirve como núcleo y que precede al verbo, como en los Ejemplos 19 y 20.

Ejemplo 19:

Equipos cientificos avanzanen la comprensióndel virus a nivel molecular, esencial para desarrollar vacunas (Galocha y Domínguez, 2020).

Ejemplo 20:

Forscher finden immer mehr über die Übertragungswege des Coronavirus heraus. Wie sich Sars-CoV-2 verbrei- tet und wie Menschen sich am besten schützen können (Uhlmann, 2020a).

Por otro lado, pese a que la noticia científica tiene el rigor que exige la ciencia, esta también incorpora, a su vez, rasgos propios de la oralidad, para proporcionarle expresividad y reducir la lejanía del texto científico. En la noticia científica se utilizan "expresiones propias de la lengua oral, con las que el emisor busca un mayor acercamiento al lector" (Hernando García-Cervigón, 2017, p. 126). Esto hace posible que, en una noticia científica, podamos encontrar estrategias comunicativas como el humor o la ironía (Gutiérrez Rodilla, 1998, p. 322). En este caso, este rasgo solo lo hemos hallado en las noticias en español, pero en ninguna de las que componen nuestro corpus de textos en alemán.

Osamos afirmar que el registro de la noticia científica en alemán no permite, al menos en el caso de nuestro corpus, la inclusión de rasgos de la lengua oral o coloquial, lo que mantiene siempre una relación jerárquica de superioridad entre el autor de la noticia y su lector, a diferencia de las noticias en español, en las que el autor, en ocasiones, intenta establecer una relación de igualdad con su lector. Por este motivo, nos es imposible ofrecer un ejemplo de este rasgo en lengua alemana, pero sí dos en español (véanse Ejemplos 21 y 22).

\section{Ejemplo 21:}

La tormenta de citoquinas causa fiebre alta, pérdidas en los vasos sanguíneos, coagulación de la sangre dentro del cuerpo, presión arterial muy baja, falta de oxígeno, exceso de acidez de la sangre y acumulación de líquido en los pulmones. En esa situación tan dramática, los glóbulos blancos se "vuelven locos" y atacan incluso al tejido sano [...] (Nieves, 2020b).

\section{Ejemplo 22:}

"A finales de año, si podemos. Quizá antes", anunció hace dos semanas el mandatario en el lanzamiento de la Operación Velocidad Warp, un despliegue 
científico sin precedentes que toma el nombre de la imaginaria velocidad superior a la de luz que alcanzan las naves espaciales en la serie televisiva Star Trek (Ansede y Galocha, 2020).

\subsection{Objetividad vs. componente ideológico}

Las noticias de divulgación científica, al estar argumentadas mediante hechos objetivos, son difícilmente manipulables. No obstante, lo que sí puede ocurrir es que, en cierto modo, la noticia de divulgación científica se vea manipulada, al no recoger toda la información o hacerlo de manera sesgada. Como afirma Cassany: "La ciencia y la divulgación también tienen ideología. No son neutras" (2006, p. 252). Basta con leer noticias de divulgación científica sobre temas controvertidos, como el uso de las células madre en la investigación médica o la validez de la homeopatía.

En la literatura disponible podemos encontrar varios estudios que abarcan la traducción periodística y la ideología, que demuestran cómo, en la traducción periodística, la ideología es razón de cambios en el TM respecto al To; por ejemplo, en el caso de la traducción de noticias del inglés al árabe (Bazzi, 2014, 2015). También Loupaki (2010) ha analizado cómo, en la traducción de noticias del inglés al griego, mediante varias técnicas de traducción (omisión, adición, neutralización, traducción literal y explicación), es posible transformar la posición de la noticia, al eliminar el conflicto ideológico, reproducirlo o cambiarlo por otro diferente.

En este ámbito, no podemos olvidar mencionar los trabajos de Valdeón (2005a, 2005b, 2007b, 2008) con los que demuestra que existen diferencias a escala estructural, sintáctica, gramatical y léxica en la traducción del inglés al español de noticias de la CNN y de la página web de BвC World y ввC Mundo, lo que le lleva a determinar que, en su análisis de la traducción de noticias, el gatekeeping "accentuates an ethnocentric view of the world whereby Anglophone news is given prominence at the expense of other more international news" (Valdeón, 2008, p. 303).

Asimismo, también existen técnicas de gatekeeping, como la omisión, la adición, la sustitución o la reorganización (Vuorinen, 1997), las cuales se ponen en práctica con el objetivo de "controlling the flow of information" (Schäffner, 2018, p. 333).

El traductor de noticias, en ocasiones, actúa a su vez como gatekeeper, término traducido como "portero de la información" por Hernández Guerrero (2009, p. 55):

[...] desde una posición más individual, ya se trate de una función derivada de su implicación profesional en la línea editorial del periódico o de una consecuencia de su propia intervención como agente transmisor de la información desde la libertad (Valdeón, 2016, p. 45).

Asimismo, el traductor puede verse obligado a tomar ciertas decisiones a la hora de traducir, para poder seguir las normas editoriales impuestas (Valdeón, 2016, p. 46), como puede ocurrir que un periódico impida o recomiende no usar ciertas palabras al hablar sobre un tema en particular.

Nuestro análisis demuestra cómo la noticia científica comparte rasgos en su versión en español y en alemán - aquellos pertenecientes al nivel léxico-semántico y los cuatro primeros del campo sintáctico-, así como también existen características propias de cada lengua, cuyo conocimiento es necesario para ofrecer una traducción de calidad. Por ejemplo, las apelaciones al lector, más comunes en español, o la inclusión de rasgos de la lengua general y coloquial, rasgo tan solo encontrado en las noticias españolas.

En las versiones de las dos lenguas percibimos cómo conviven un tono informativo con el didáctico, aunque prima lo informativo sobre lo didáctico en la lengua alemana, al contrario que en español, que sí está más equilibrado. 
Pese a lo que podríamos pensar antes de abordar este estudio, en ambas lenguas está presente la ideología, pues en todos los periódicos que componen los dos corpus se ha dado un tratamiento diferente al episodio en el que el presidente de Estados Unidos, Donald Trump, proponía luchar contra el coronavirus "ingiriendo lejía". Algunos medios, en su labor de gatekeeping, no se han hecho eco de la noticia, mientras otros lo han recogido como un malentendido entre la recepción por parte de la sociedad y la manera de hablar del presidente. Otros medios, dada la forma en la que describen la noticia, en cierto modo, ponen en duda el valor de Trump como presidente y su labor de gestión ante la crisis sanitaria.

Por ejemplo, El Mundo (2020) expone en su noticia que la afirmación de Trump fue equivocada y se suman a las palabras del neumólogo Vin Gupta para desmentirla. No obstante, en la noticia, el periódico intenta explicar, al lanzar la pregunta: "Pero, ¿qué es lo que exactamente dijo el mandatario de EEUU?", qué y cómo ocurrió para justificar el comportamiento de Trump, alegando que este, al escuchar las declaraciones de Deborah Birx, coordinadora de la estrategia sobre el coronavirus de la Casa Blanca, lanzó esa propuesta con el fin de ayudar. En este caso, en la noticia se puede apreciar un tono que intenta quitar peso al asunto y hacer ver que Trump cometió un pequeño error al proponer esa idea, la cual se ha magnificado.

Por otro lado, El País (Guimón, 2020), al informar sobre el incidente, ya se refiere a este con adjetivos negativos, describiéndolo como "Trump realizó esta dudosa aportación" y además recopila otras declaraciones del presidente que siguen la misma línea y advierte de su poca cautela y mala praxis: "El presidente ya dijo que el virus desaparecería <milagrosamente> con la llegada del calor y también ha dado pábulo con anterioridad a hipótesis científicas no contrastadas. El peligro es evidente". El País incluso llega a tildar de espectáculo la gestión del presidente: "Trump ha converti- do su comparecencia diaria ante las cámaras en un auténtico reality show". Por ello, en este caso vemos cómo El País es más crítico con la actitud de Trump y en ningún momento justifica su declaración o gestión de la pandemia, sino que la crítica aún más, aportando pruebas.

También podemos afirmar que tanto en español como en alemán, las noticias científicas que componen nuestro corpus presentan la misma estructura y, en ambos casos, la longitud es variable, no existe una extensión media predeterminada.

\section{Conclusiones}

Tras revisar los resultados de nuestro análisis, podemos determinar que la traducción de la noticia científica entraña una amplia serie de dificultades. Uno de los retos al que nos enfrentamos como traductores es reescribir el texto tal y como hizo el periodista científico, manteniendo en todo momento la misma densidad terminológica que el original y sin aumentar la dificultad de su comprensión. Para ello, el traductor debe ser muy meticuloso y cuidadoso con las traducciones que hace, sobre todo del uso de la terminología especializada, ya que esta, aunque se encuentre en un texto que transmite conocimiento científico a través de un método y sus resultados, debe ser inteligible. Así, el traductor de noticias científicas debe conocer a la perfección la terminología del campo temático de la noticia para, de este modo, mantener la reformulación que ya hizo el periodista al escribir el To y evitar eliminar esos nudos o conexiones (Cassany et al., 2000, p. 79).

Nuestros resultados evidencian con claridad que la traducción de la noticia científica transciende lo meramente lingüístico, entrando en juego otros elementos, como la ideología. Asimismo, el número de rasgos que comparten ambas lenguas analizadas es alto, aunque sí hemos advertido diferencias a las que debemos prestar atención, como, por ejemplo, el uso de 
elementos tipográficos, como el paréntesis y la raya, el uso de los tiempos verbales (verbos $d i$ cendi) o las construcciones en las que se apela al lector. Estas diferencias y matices nos dicen que, en el caso del alemán, queda más patente la relación jerárquica entre escritor-lector. En cambio, en las noticias científicas analizadas en español, se intenta establecer una relación de igualdad entre escritor-lector.

Por otro lado, el carácter de la noticia en alemán es más informativo, en detrimento de lo didáctico, no sabemos si es porque la tradición científica en Alemania está más consolidada que en España, o si se debe a que se concibe el texto como un ejercicio de comprensión activo, en el que el lector se documente por sí mismo si lo estima oportuno.

Además, y debido a que hemos elegido un campo temático muy concreto - el coronavirus-, no hemos localizado, en ninguno de los casos, el uso de préstamos o extranjerismos, los cuales, como lectores de PC en ambos idiomas, nos consta que sí son frecuentes en otros campos, como la tecnología, por ejemplo.

Por último, este apunte evidencia y nos sirve para concluir que, aunque este estudio arroja luz sobre cómo proceder en la traducción de la noticia científica y sus rasgos en español y alemán, sigue siendo necesario un análisis contrastivo alemán-español de la noticia científica, en el que se abarquen otros campos, así como del Pc en general, y en el que se incluyan otros géneros, como la entrevista científica o el editorial.

\section{Referencias}

Andújar Moreno, G. (2009). Traducir la argumentación en editoriales de prensa: de las estrategias argumentativas a las técnicas traductoras. Hermēneus. Revista de Traducción e Interpretación, (11), 51-80. http://www5.uva.es/hermeneus/hermeneus/11/arti02_11.pdf
Avogadro, M. (2005). Periodismo de la ciencia: aproximaciones y cronología. Razón y Palabra, 10(43): 1-15. https://www.redalyc.org/ pdf/1995/199520626011.pdf

Baya Essayani, M.-L. (2005). Traducción de textos periodísticos: español-árabe: diez años de experiencia en una agencia internacional de noticias. En M. A. García Peinado, M. Campos Plaza, E. Ortega Arjonilla y C. Vilvandre de Sousa (Eds.), El español, lengua de cultura, lengua de traducción: aspectos teóricos, metodológicos $y$ profesionales (pp. 405-414). Atrio.

Bazzi, S. (2014). Foreign metaphors and Arabic translation: An empirical study in journalistic translation practice. Journal of Language and Politics, 13(1), 120-151. https://doi. org/10.1075/jlp.13.1.06baz

Bazzi, S. (2015). Ideology and Arabic translations of news texts. Translation and Translanguaging in Multilingual Contexts, 1(2), 135-161. https:// doi.org/10.1075/ttmc.1.2.01baz

Bielsa, E. (2007). Translation in global news agencies. Target, 19(1), 135-155. https://doi. org/10.1075/target.19.1.08bie

Bielsa, E. (2010). Translating news: A comparison of practices in news agencies. En R. A. Valdeón (Ed.), Translating information (pp. 31-49). Ediuno.

Bielsa, E. y Bassnett, S. (2009). Translation in global news. Routledge.

Calvo Hernando, M. (1997). Manual de periodismo científico. Bosch.

Campos, O. (2013). Procedimientos de desterminologización: traducción y redacción de guías para pacientes. Panace@, 14(37), 48-52. https://www.tremedica.org/panacea/v14-n37junio-2013/

Carbonell, O. (2010). Análisis de pautas de traducción ideológica en el discurso periodístico. En R. A. Valdeón (Ed.), Translating information (pp. 87-123). Ediuno.

Carbonell, O. y Khadija, M. (2005). Las huellas de la ideología. Terrorismo e islam en los medios de comunicación. En C. Cortés Zaborras y M. J. Hernández Guerrero (Eds.), La traducción periodística (pp. 199-235). Universidad de Castilla-La Mancha. 
Casado Velarde, M. (2006). Introducción a la gramática del texto del español (5. ${ }^{a}$ ed.). Arco Libros.

Cassany, D. (2006). Tras las líneas. Sobre la lectura contemporánea. Anagrama.

Cassany, D. (2012). En-línea. Leer y escribir en la red. Anagrama.

Cassany, D., López, C. y Martí, J. (2000). La transformación divulgativa de redes conceptuales científicas. Hipótesis, modelo y estrategias. Revista Iberoamericana de Discurso y Sociedad, 2(2), 73-103. https://www.researchgate.net/ publication/275034470_La_transformacion_ divulgativa_de_redes_conceptuales_cientificas_hipotesis_modelo_y_estrategias

Cervera Rodríguez, A. (2017). Estrategias lingüístico-discursivas en la entrevista científica. En L. A. Hernando Cuadrado y J. Sánchez Lobato (Eds.), La configuración lingüístico-discursiva en el periodismo científico (pp. 137-167). Iberoamericana Vervuert.

Delgado Pugés, I. y Barceló Martínez, T. (2011). El proceso de documentación en el aula de traducción económica (francés-español): recopilación de recursos electrónicos sobre el mundo de la empresa. Çédille: Revista de Estudios Franceses, (7), 116-136. https://cedille.webs.ull.es/7/07delgadobarcelo.pdf

Diezhandino Nieto, M. P. (1997). Especialización y periodismo de servicio. En F. Esteve Ramírez (Ed.), Estudios sobre información periodistica especializada (pp. 59-65). Fundación Universidad San Pablo-ceU.

El Mundo. (2020, abril 24). Donald Trump sugiere tratar el Covid-19 con inyecciones de desinfectante. El Mundo. https://www.elmundo. es/internacional/2020/04/24/5ea291adfc6c8309298b45ae.html

Enguix Oliver, S. (2015). Periodismo especializado y especialización en política. Mediaciones Sociales, (14), 103-128. https://doi.org/10.5209/ rev_MESO.2015.n14.51561

Espejo Cala, C. (2013). Gacetas y relaciones de sucesos en la segunda mitad del xvII: una comparativa europea. En P. M. Cátedra (Ed.), Gé- neros editoriales y relaciones de sucesos en la Edad Moderna (pp. 71-88). SEMYR.

Esteve Ramírez, F. (1999). Áreas de especialización. Fragua.

Esteve Ramírez, F. (2010). Fundamentos de la especialización periodística. En I. Camacho (Ed.), La especialización en periodismo. Formarse para informar (pp. 11-26). Comunicación Social.

eurostat. (2019, septiembre 2). SDGs \& me: Industry, innovation and infrastructure.

Fayard, P. (1998). La communication scientifique publique : de la vulgarisation à la médiatisation. Chronique Sociale.

Fernández del Moral, J. y Esteve Ramírez, F. (1993). Fundamentos de información periodística especializada. Síntesis.

Fundéu. (2020). La CovID-19, nombre de la enfermedad del coronavirus. https://www.fundeu.es/ recomendacion/covid-19-nombre-de-la-enfermedad-del-coronavirus/

García González, J. E. (2004). La traducción de los titulares periodísticos del inglés al español: análisis contrastivo. En V. Pacheco Costa (Ed.), Acerca de la traducción y la interpretación. Actas del II Congreso de traducción e interpretación (pp. 56-62). CEADE.

García González, J. E. (2005). Palabra, espacio y tiempo. En C. Cortés Zaborras y M. J. Hernández Guerrero (Eds.), La traducción periodistica (pp. 137-154). Universidad de Castilla-La Mancha.

García Suárez, J. E. (2005). Noticias de agencia: algunos problemas planteados en la traducción español-árabe. En C. Cortés Zaborras y M. J. Hernández Guerrero (Eds.), La traducción periodística (pp. 175-197). Universidad de Castilla-La Mancha.

Giné M. y Hibbs-Lissorgues, S. (Eds.). (2010). Traducción y cultura. La literatura traducida en la prensa hispánica (1868-98). Peter Lang Verlag.

Guimón, P. (2020, abril 24). Trump sugiere tratar el coronavirus con "una inyección de desinfectante" o con "luz solar". El País. https:// elpais.com/internacional/2020-04-24/trum- 
p-sugiere-tratar-el-coronavirus-con-una-inyeccion-de-desinfectante-o-con-luz-solar.html

González Pérez, R. (2017). Reescribir la ciencia: la configuración lingüístico-discursiva de los artículos de divulgación científica. En L. A. Hernando Cuadrado y J. Sánchez Lobato (Eds.), La con $\square$ guración lingüístico-discursiva en el periodismo cientifico (pp. 80-105). Iberoamericana Vervuert.

Graiño Knobel, S. (2015). Un modelo teórico para la traducción en el periodismo científico. $\mathrm{Pa}$ nace@, 16(42), 190-194. https://www.tremedica.org/wp-content/uploads/n42_tribunaGrainoKnobel.pdf

Gutiérrez Rodilla, B. M. (1998). La ciencia empieza en la palabra. Análisis e historia del lenguaje científico. Península.

Hernández Guerrero, M. J. (1997). La traducción en la prensa: los artículos de opinión. En E. Morillas y J. P Arias (Eds.), El papel del traductor (pp. 319-340). Colegio de España.

Hernández Guerrero, M. J. (2004). La traducción de los titulares periodísticos. En J. Suso López y R. López Castillo (Eds.), Le français face aux défis actuels. Histoire, langue et culture (Vol. 2, pp. 271-281). Universidad de Granada.

Hernández Guerrero, M. J. (2005a). La traducción de los géneros periodísticos. En C. Cortés Zaborras y M. J. Hernández Guerrero (Eds.), La traducción periodística (pp. 89-135). Universidad de Castilla-La Mancha.

Hernández Guerrero, M. J. (2005b). Prensa y traducción. En C. Cortés Zaborras y M. J. Hernández Guerrero (Eds.), La traducción periodistica (pp. 157-175). Universidad de Castilla-La Mancha.

Hernández Guerrero, M. J. (2006a). El recurso a la traducción compilada en la prensa escrita. En P. Blanco García y P. Martino Alba (Eds.), Traducción y multiculturalidad (pp. 365-372). Instituto Universitario de Lenguas Modernas y Traductores, Universidad Complutense de Madrid.

Hernández Guerrero, M. J. (2006b). Técnicas específicas de la traducción periodística. Quaderns: Revista de Traducció, (13), 125-139. https://
www.raco.cat/index.php/QuadernsTraduccio/article/view/51667/55312

Hernández Guerrero, M. J. (2008a). La traducción de la información científica en la prensa española: el diario El Mundo. Sendebar, 19, 167188. https://revistaseug.ugr.es/index.php/ sendebar/article/view/668/760

Hernández Guerrero, M. J. (2008b). La traducción periodística en los diarios españoles de información general. En L. Pegenaute, J. Decesaris, M. Tricás y E. Bernal (Eds.), Actas del III Congreso Internacional de la Asociación Ibérica de Estudios de Traducción e Interpretación: La traducción del futuro: mediación lingüistica y cultural en el siglo XXI (Vol. 2, pp. 359-368). PPU.

Hernández Guerrero, M. J. (2008c). Los artículos de opinión traducidos en la prensa escrita: el trasvase transcultural de la opinión. En M. J. Hernández Guerrero y S. Peña Martín (Eds.), La traducción, factor de cambio (pp. 93-113). Peter Lang Verlag.

Hernández Guerrero, M. J. (2009). Traducción y periodismo. Peter Lang Verlag.

Hernández Guerrero, M. J. (2010). Las noticias traducidas en el diario El Mundo: el trasvase transcultural de la información. En R. A. Valdeón (Ed.), Translating information (pp. 51-86). Ediuno.

Hernández Guerrero, M. J. (2013). Traducción y divulgación científica. Las revistas semanales de la prensa española. Skopos, 3, 63-73. https://www.uco.es/ucopress/ojs/index. php/skopos/article/view/4389/4156

Hernando Cuadrado, L. A. (2017). Del registro científico al discurso periodístico de información y divulgación de la ciencia. En L. A. Hernando Cuadrado y J. Sánchez Lobato (Eds.), La configuración lingüistico-discursiva en el periodismo científico (pp. 17-46). Iberoamericana Vervuert.

Hernando Cuadrado, L. A. y Hernando GarcíaCervigón, A. (2006). Lengua y comunicación en el discurso periodístico de divulgación cientifica $y$ tecnológica. Fragua.

Hernando García-Cervigón, A. (2007). E1 discurso científico y tecnológico y la lengua española. En R. Sarmiento y F. Vilches (Ed.), Neologismos y sociedad del conocimiento. Funciones de la 
lengua en la era de la globalización (pp. 153-165). Ariel.

Hernando García-Cervigón, A. (2017). La configuración lingüística del discurso en la noticia científica. En L. A. Hernando Cuadrado y J. Sánchez Lobato (Eds.), La configuración lingüistico-discursiva en el periodismo científico (pp. 107-135). Iberoamericana Vervuert.

López Cubino, R., López Sobrino, B. y Bernabeu Morón, M. (2009). El periódico. Proyecto Mediascopio Prensa. La lectura de la prensa escrita en el aula. Centro de Investigación y Documentación Educativa (CIDE). https://sede. educacion.gob.es/publiventa/el-periodico-proyecto-mediascopio-prensa-la-lectura-de-la-prensa-escrita-en-el-aula/ensenanza-prensa/12422

Loupaki, E. (2010). Investigating translators' strategies in rendering ideological conflict: The case of news translation. En C. Schäffner y S. Bassnett (Eds.), Political discourse, media and translation (pp. 55-75). Cambridge Scholars Publishing.

Mercado Sáez, M. T. (2010). Aportaciones teóricas en torno al concepto de periodismo especializado. Question, 1(28): 1-12. https://perio. unlp.edu.ar/ojs/index.php/question/article/ view/1081

Myers, G. (1990). Writing biology. Texts in the social construction of scientific knowledge. University of Winconsin Press.

Navarro, A. (2014). Las intervenciones del sujeto traductor en la Gaceta de Caracas (1808-1822) (Tesis doctoral). Université de Montréal, Canadá.

Portolés Lázaro, J. (2001). Marcadores del discurso. Ariel.

Puigvert Ocal, A. (2017). Procedimientos léxico-discursivos y de estructuración semántica en el periodismo de divulgación científica en prensa y revistas digitales. En L. A. Hernando Cuadrado y J. Sánchez Lobato (Eds.), La configuración lingüiśtico-discursiva en el periodismo cientifico (pp. 169-193). Iberoamericana Vervuert.

Ramírez Almansa, I. (2018). Periodismo especializado y traducción: la traducción alemán-es- pañol de artículos sobre vitivinicultura. En C. Fortea, M. J. Gea, C. Gómez Pérez, M. Guirao, E. Maqueda, M. Marotta y A. Roales (Eds.), Nuevas perspectivas en traducción e interpretación (pp. 23-29). Guillermo Escolar.

Ramírez Almansa, I. (2021). Metodología para la traducción alemán-español del periodismo especializado en vitivinicultura. En M. C. Balbuena Torezano (Ed.), Enoturismo, lingüística y traducción especializada (En prensa). Síntesis.

Real Academia Española. (2020). Crisis del covID-19: sobre la escritura de "coronavirus". https://www. rae.es/noticias/crisis-del-covid-19-sobre-la-escritura-de-coronavirus

Real Academia Nacional de Medicina de España (2020). Coronavirus, claves de escritura. https://www.ranm.es/terminolog\%C3\%ADa-m\%C3\%A9dica/recomendaciones-de-la-ranm/4582-coronavirus-claves-de-escritura. html

Reque de Coulon, A. (2002). Análisis de estrategias y procedimientos de traducción utilizados en los títulos de la versión española de $L e$ Monde diplomatique. Hermēneus, (4), 147-159. https://recyt.fecyt.es/index.php/HS/article/ view/6108

Robles Ávila, S. (2017). El léxico en el periodismo de divulgación: entre el rigor científico

y el sensacionalismo informativo. En L. A. Hernando Cuadrado y J. Sánchez Lobato (Eds.), La configuración lingüistico-discursiva en el periodismo científico (pp. 195-228). Iberoamericana Vervuert.

Salazar Herrera, R. M. (2006). Hacia un periodismo especializado, ágil y creativo: la experiencia de la revista de transportes Señales (1996-1998) (Tesis doctoral). Universidad Nacional Mayor de San Marzos, Lima, Perú.

Schäffner, C. (2018). Language, interpreting, and translation in the news media. En K. Malmkjaer (Ed.), The Routledge Handbook of Translation Studies and Linguistics (pp. 327-341). Routledge.

Toro Santos, A. R de y Cancelo López, P. (Coords.). (2008). Teoría y práctica de la traducción en la prensa periódica española (1900-1965). Diputación Provincial de Soria. 
Valdeón, R. A. (2005a). The cNN en Español News. Perspectives, 13(4), 255-267. https://doi. org/10.1080/09076760608668996

Valdeón, R. A. (2005b). The "translated" Spanish service of the BвC. Across Languages and Cultures, 6(2), 195-220. https://www.researchgate.net/publication/250006638_The_Translated_Spanish_Service_of_the_BBC

Valdeón, R. A. (2007a). Political and sexist bias in news translation: Two case studies. TRANS. Revista de Traductología, (11), 231-243. https:// doi.org/10.24310/TRANS.2007.v0i11.3110

Valdeón, R. A. (2007b). Ideological independence or negative mediation: BBC Mundo and CNN en Español's (translated) reporting of Madrid's terrorist attacks. En M. Salama-Carr (Ed.), Translating and interpreting conflict (pp. 99-118). Rodopi.

Valdeón, R. A. (2007c). Translating news from the inner circle: Imposing regularity across cultures. Quaderns: Revista de Traducció, 14, 155-167. https://www.raco.cat/index.php/QuadernsTraduccio/article/view/70322/80557

Valdeón, R. A. (2008). Anomalous news translation: Selective appropriation of themes and texts in the internet. Babel, 54(4), 299-326. https://doi.org/10.1075/babel.54.4.01val

Valdeón, R.A. (2016). Traducción periodística y gatekeeping. En R. Martín Ruano y A. Vidal Claramonte (Eds.), Traducción, medios de comunicación y opinión pública (pp. 35-51). Comares. https://www.researchgate.net/publication/305655797_Traduccion_periodistica_y_gatekeeping

Vuorinen, E. (1997). News translation as gatekeeping. En M. Snell-Hornby, Z. Jettmarova y K. Kaindl (Eds.), Translation as intercultural communication. Selected papers from the EST Congress, Prague 1995 (pp. 161-171). John Benjamins.

Yriart, M. F. (1990). La divulgación de las ciencias como problema comunicacional. Arbor. Ciencia, Pensamiento y Cultura, (534-535), 163-178.

\section{Anexo. Corpus de noticias}

\section{Noticias en español}

Ansede, M. (2020, junio 5). Hallados "cientos" de nuevos coronavirus en murciélagos de
China. El Pais. https://elpais.com/ciencia/2020-06-04/hallados-cientos-de-nuevoscoronavirus-en-murcielagos-de-china.html

Ansede, M. y Galocha, A. (2020, mayo 31). La vacuna: el único camino de regreso a la vida anterior. El País. https:// elpais.com/elpais/2020/05/30/ciencia/1590828979_735960.html

Biosca, P. (2020, mayo 14). La propagación "silenciosa" del Covid-19: ¿por qué el coronavirus se expande sin síntomas? ABC. https://www. abc.es/ciencia/abci-propagacion-silenciosa-covid-19-coronavirus-expande-sin-sintomas-202005132053_noticia.html\#vca=mod-sugeridos-p2\&vmc $=$ relacionados \&vso=la-propagacion-silenciosa-del-covid-19-por-que-el-coronavirus-se-expande-sin-sintomas\&vli=noticia.foto.ciencia

Cortés, A. (2020a, marzo 6). Una prueba de cuatro horas que tarda días en realizarse. El País. https://elpais.com/ciencia/2020-03-05/una-reaccion-en-cadena-delata-al-coronavirus. html

Cortés, A. (2020b, marzo 13). Los mayores retos para conseguir una vacuna contra el coronavirus. El País. https://elpais.com/ciencia/2020-03-13/los-cinco-retos-para-conseguir-una-vacuna-contra-el-coronavirus.html

Galocha, A y Domínguez, N. (2020, marzo 11). Así infecta el coronavirus. El País. https://elpais.com/elpais/2020/03/06/ciencia/1583515780_532983.html

Ley, M. (2020, mayo 31). Así ha sido la evolución del Covid-19 en cada zona sanitaria de Madrid. El Mundo. https://www.elmundo.es/madrid/2020/05/31/5ed0f630fc6c83e3498b4570. html

López Sánchez, G. (2020a, abril 29). ¿Por qué la vacuna para el Covid-19 está tardando tanto? ABC. https://www.abc.es/ciencia/abci-vacuna-para-covid-19-esta-tardando-tanto-202004290154_noticia.html

López Sánchez, G. (2020b, marzo 30). ¿Puede el coronavirus mutar y hacerse más letal? $A B C$. https://www.abc.es/ciencia/ abci-puede-coronavirus-mutar-y-hacerse-mas-1etal-202003290048_noticia. $\mathrm{html} \# \mathrm{vca}=$ mod-sugeridos-p $3 \& \mathrm{vmc}=$ rel- 
acionados\&vso=puede-el-coronavirus-mutar-y-hacerse-mas-letal\&vli=noticia.foto.ciencia

Lucio, C. (2020, marzo 31). ¿Es alergia o coronavirus? Estas son las claves para diferenciar los síntomas. El Mundo. https://www.elmundo. es/ciencia-y-salud/salud/2020/03/31/5e8220defdddff04a98b4642.html

Nieves, J. M. (2020a, mayo 12). Hallan en murciélagos un virus muy similar al SARs-CoV-2. $A B C$. https://www.abc.es/ciencia/abci-hallan-murcielagos-virus-similar-sars-cov-2-202005122033_noticia. $\mathrm{html} \# \mathrm{vca}=$ mod-sugeridos-p $3 \& \mathrm{vmc}=$ relacionados \&vso=hallan-en-murcielagos-un-virus-muy-similar-al-sars-cov-2\&vli=noticia. foto.ciencia

Nieves, J. M. (2020b, mayo 19). ¿Cómo mata el coronavirus? Los científicos siguen sin saberlo. $A B C$. https://www.abc.es/ciencia/abci-como-mata-coronavirus-cientificos-siguen-sin-saberlo-202005142031_noticia.html

Nieves, J. M. (2020c, mayo 22). Hallan el "talón de Aquiles" del coronavirus SARs-CoV-2. $A B C$. https://www.abc.es/ ciencia/abci-hallan-talon-aquiles-coronavirus-sars-cov-2-202005212100_noticia.html

Nieves, J. M. (2020d, abril 16). ¿Cómo mata el coronavirus? No saberlo dificulta hallar un tratamiento efectivo. $A B C$. https://www.abc.es/ ciencia/abci-como-mata-coronavirus-no-saberlo-dificulta-hallar-tratamiento-efectivo-202004162107_noticia.html

Sevillano, E. (2020, mayo 31). Los epidemiólogos sobre los test masivos de Torrejón: "No tienen justificación científica". El País. https:// elpais.com/sociedad/2020-05-31/los-epidemiologos-sobre-los-test-masivos-de-torrejon-no-tienen-justificacion-cientifica.html

\section{Noticias en alemán}

Bartens, W. (2020, abri19). Die typischen Symptome des Coronavirus. Süddeutsche Zeitung. https:// www.sueddeutsche.de/gesundheit/coronavirus-symptome-verlauf-covid-19-1.4851200

Charisius, H. y Endt, C. (2020, abril 23). Die verborgenen Toten. Süddeutsche Zeitung. https:// www.sueddeutsche.de/wissen/coronavirus-uebersterblichkeit-pandemie-statistik-tote-1.4884804

Ehemann, A. (2020, mayo 1). Die Angst vor der Kita-Öffnung. ZEIT ONLINE. https://www. zeit.de/wissen/gesundheit/2020-04/coronavirus-kinder-infektionsrisiko-schuloeffnung-christan-drosten

Hecking, C. (2020, mayo 14). Gefährlicher Geiz. SPIEGEL. https://www.spiegel.de/wissenschaft/mensch/corona-testkapazitaetenwerden-nicht-genutzt-gfaehrlicher-geiz-a97e2fc79-7ed6-468c-9107-1d30658aeb9c

Köppe, J. (2020a, mayo 20). Corona im Nerzmantel. SPIEGEL. https://www.spiegel.de/ wissenschaft/medizin/corona-nerz-sollmensch-angesteckt-haben-wie-infektioessind-tiere-a-7b44d77e-bc3d-46dc-a3e 71d62ddad5092

Köppe, J. (2020b, mayo 28). Auch Deutschland unterbricht Studie mit Malariamittel. SPIEGEL. https://www.spiegel.de/wissenschaft/medizin/corona-auch-deutschland-pausiert-studiemit-hydroxychloroquin-gegen-covid-19-a-7efceb53-e957-44b6-83fa-ef322de2c814

Kupferschmidt, K. (2020, mayo 29). Jeder könnte Superspreader sein. ZEIT ONLINE. https://www. zeit.de/wissen/gesundheit/2020-05/coronavirus-ansteckung-covid-19-patienten-schutzmassnahmen-infektionsherde/komplettansicht

Le Ker, H. (2020, junio 9). Blutgruppe könnte Krankheitsverlauf von Covid-19 beeinflussen. SPIEGEL. https://www.spiegel.de/ wissenschaft/medizin/coronavirus-beeinflusst-die-blutgruppe-den-krankheitsverlauf-a818f0aac-a788-4b5a-b203-e8196d747ae2

Simmank, J. (2020, mayo 14). Die Wege des Virus. ZEIT ONLINE. https://www.zeit.de/ zustimmung?url=https $\% 3 \mathrm{~A} \% 2 \mathrm{~F} \% 2 \mathrm{~F}$ www.zeit.de\% $\%$ Fwissen $\% 2$ Fgesundheit $\% 2$ F2020-05\%2Fsars-cov-2-coronavirus-verlauf-lungenkrankheit-herz-blut-rachen

Simmank, J., Grabar, E. y Fischer, L. (2020, abril 9). Wann kommt die Impfung? ZEIT ONLINE. https://www.zeit.de/wissen/gesundheit/2020-04/sars-cov-2-impfstoff-forschung-beschleunigung-coronavirus 
Stukenberg, K. (2020, mayo 27). Mit viel Geld gegen das Virus. SPIEGEL. https://www.spiegel. $\mathrm{de} /$ wissenschaft/medizin/corona-krise-mitviel-geld-gegen-das-virus-a-f000e4e9-e1ce4555-9238-72ef2c4eb82e

Uhlmann, B. (2020a, abril 7). Wo das Infektionsrisiko groß ist. Süddeutsche Zeitung. https://www. sueddeutsche.de/gesundheit/coronavirus-covid-19-ansteckung-anstecken-1.4869925

Uhlmann, B. (2020b, mayo 27). Die Tücken der Corona-Tests. Süddeutsche Zeitung. https:// www.sueddeutsche.de/gesundheit/coronavirus-tests-falsches-ergebnis-1.4919503
Weber, N. (2020, junio 4). Gibt es eine "immunologische Dunkle Materie" in Deutschland? SPIEGEL. https://www.spiegel.de/wissenschaft/ medizin/corona-these-von-britischem-forscher-gibt-es-eine-immunologische-schwarze-materie-in-deutschland-a-c3fad684-be0a47ba-b88c-8aa02aa1c298

Zinkant, K. (2020, mayo 12). Neues Testverfahren für Covid-19 mit Genschere. Süddeutsche Zeitung. https://www.sueddeutsche.de/gesundheit/crispr-test-coronavirus-genschere-1.4905054

Cómo citar este artículo: Ramírez-Almansa, I. (2021). Análisis contrastivo (alemán-español) para la traducción del periodismo especializado en ciencia: las noticias de divulgación científica sobre coronavirus. Mutatis Mutandis, Revista Latinoamericana de Traducción, 14(1), 240-265. https://doi.org/10.17533/udea.mut.v14n1a10 